\title{
Corpos e imaginação em movimento brincante: teatro e literatura na formação de professores
}

\author{
Bodies and imagination in playing movement: \\ theater and literature in teacher training
}

\section{Cuerpos e imaginación en movimiento brincante:} teatro y literatura en la capacitación docente

\author{
SIMONE CRISTIANE SILVEIRA CINTRA* \\ Prefeitura Municipal de Florianópolis, Florianópolis- SC, Brasil. \\ ELIANE SANTANA DIAS DEBUS ${ }^{* *}$ \\ Universidade Federal de Santa Catarina, Florianópolis- SC, Brasil.
}

\begin{abstract}
RESUMO: O artigo publiciza formação de extensão com um grupo de 28 estudantes do Curso de Pedagogia, da Universidade Federal de Santa Catarina, no segundo semestre de 2011, vivenciando experiências expressivas com a linguagem teatral e a literatura produzida para a infância. O período, embora curto, contribuiu para a ressignificação e expressão de ideias, sentimentos e conhecimentos das futuras professoras, não ocorrendo somente pelas formas linguísticas que informam, mas, também, por aquelas que potencializam a imaginação.
\end{abstract}

Palavras-chave: Literatura. Teatro. Infância. Formação de professores.

\begin{abstract}
The article reports extension training with a group of 28 students from the Pedagogy Course, of the Federal University of Santa Catarina, on the second semester of 2011, experiencing expressive experiences with theatrical language and literature produced for
\end{abstract}

\footnotetext{
* Doutora e mestre em Educação pela Universidade Estadual de Campinas. É graduada em Pedagogia. Professora e integrante do Núcleo de Formação, Pesquisa e Assessoramento da Educação Infantil (NUFPAEI) da Rede Municipal de Ensino de Florianópolis. Pesquisadora do Grupo de Pesquisa em Literatura Infantil e Juvenil e Práticas de Mediação Literária (Literalise). E-mail: <simonescintra@gmail.com>.

** Doutora em Linguística e Letras pela Pontifícia Universidade Católica do Rio Grande do Sul e mestre em Literatura pela Universidade Federal de Santa Catarina. Atualmente é professora da Universidade Federal de Santa Catarina. É líder do Grupo de Pesquisa em literatura Infantil e Juvenil e Práticas de Mediação Literária (Literalise). E-mail:<elianedebus@hotmail.com>.
} 
childhood. The length of time, even though short, contributed to the re-signification and expression on ideas, feelings and knowledge of future teachers, not only for the linguistic form they report, but also for those that enhance imagination.

Keywords: Literature. Theater. Childhood. Teacher training.

RESUMEN: El artículo divulga formación de extensión con un grupo de 28 estudiantes del Curso de Pedagogía, de la Universidad Federal de Santa Catarina, en el segundo semestre de 2011, vivenciando experiencias expresivas con el lenguaje teatral y la literatura producida para la infancia. El período, aunque corto, contribuyó a la resignificación y expresión de ideas, sentimientos y conocimientos de las futuras profesoras, no ocurriendo sólo por las formas lingüísticas que informan, sino también por aquellas que potencian la imaginación.

Palabras clave: Literatura. Teatro. Infancia. Capacitación docente.

\section{Introdução}

Criança brincando é abelha colhendo néctar. Brincadeira é néctar armazenado na alma. Quando você cresce, as brincadeiras se recolhem em algum lugar do teu ser, você passa a cuidar de coisas mais custosas, mas as brincadeiras sempre zêm te visitar, mesmo que você não perceba.

Eloí Bocheco

$\mathrm{T}$ ecemos nosso texto no entrelaçar do vivido e das perspectivas que temos sonhado e buscado construir na e para a formação e as práticas pedagógicas de professora(e)s de crianças, em especial, de crianças de educação infantil. Formação e práticas pedagógicas nutridas pela arte e pela brincadeira que, na prosa poética de Eloí Bocheco (2013), é o néctar colhido na infância e armazenado na alma de todos nós adultos.

$\mathrm{O}$ vivido a que nos referimos se deu em meio a encontros e reencontros ocorridos entre nós, autoras deste texto, entre nós e estudantes, todas mulheres, do curso de Pedagogia da Universidade Federal de Santa Catarina (UFSC), com as quais desenvolvemos experiências expressivas com a linguagem teatral e a literatura produzida para a infância. E entre as estudantes e suas dimensões brincantes, imaginativas, criadoras e poéticas. 
Tudo começou com uma parceria de trabalho junto a um projeto de extensão no qual desenvolvíamos ações de formação continuada com professoras e bibliotecárias da Secretaria de Educação de Florianópolis. Das ideias e questões suscitadas durante esse primeiro encontro vislumbramos outras tantas e a partir delas iniciamos a experiência de formação inicial de professoras de crianças que aqui partilhamos. Essa experiência fez parte da pesquisa de pós-doutorado que teve como tema e foco a formação artístico-cultural de estudantes de pedagogia e as inter-relações entre esta formação e a construção de saberes e fazeres docentes. Durante a pesquisa foram realizadas diferentes práticas de formação. Trazemos para este texto algumas das histórias vividas em um curso de extensão facultativo e destinado a estudantes de todas as fases do curso de Pedagogia da UFSC, sem pré-requisito ou processo seletivo.

Ao começarmos as atividades desse curso, no primeiro encontro com o grupo, formado por vinte e oito estudantes, tivemos a dimensão de que aquele se tratava de um reencontro nosso com a maioria das participantes. Somente as estudantes da $1^{\mathrm{a}}$ fase do curso não tinham participado de disciplinas ou oficinas por nós ministradas em outros espaços da universidade. Esse nos pareceu um dado importante, pois a escolha da maioria das estudantes em participar do nosso curso estava relacionada ao desejo de dar continuidade ao que já haviam conosco experimentado. Dar continuidade às vivências expressivas com o teatro e a literatura produzida para a infância.

Pudemos observar, com o decorrer das aulas, que o desejo era realmente significativo, e que isso imprimia ao trabalho uma atmosfera de aceitação e entrega que contagiava as estudantes mais tímidas ou menos acostumadas a realizar atividades de fruição e de criação artística. Um contágio muito bom, mas que não conteve dificuldades e desafios vivenciados pelas estudantes ao experienciar as linguagens da arte e, em especial, ao partilhar processos imaginativos e de faz de conta entre adultos.

Entretanto, apesar e também impulsionadas pelos desafios, as experiências vividas durante o curso produziram histórias de corpos e imaginação de gente grande, em movimento brincante. Narramos, a seguir, algumas dessas histórias na intenção que possam provocar "outras histórias para que se produzam outros sentidos, outras relações, outros nexos" (PRADO; SOLIGO, 2005, p.53) na vida, na formação e nas práticas pedagógicas daquela(e)s que convivem ou irão conviver com as crianças pequenas nos espaços coletivos de educação e cuidado.

\section{Teatro e literatura para a infância}

Nossa experiência de formação aconteceu em sete encontros, com duas horas e trinta minutos de duração, organizados a partir do desejo de proporcionar às estudantes uma vivência significativa com elementos da linguagem teatral e da literatura para a 
infância, potencializando, assim, experiências de fruição literária e de criação cênica. As atividades vivenciadas estiveram pautadas em elementos da linguagem teatral (elaboradas a partir do sistema de jogos teatrais de Viola Spolin ${ }^{1}$; de brincadeiras tradicionais e de práticas corporais e vocais) e em propostas de criações cênicas junto à fruição de narrativas e poemas para a infância.

\section{Histórias de corpo inteiro}

Todos os encontros eram iniciados com um trabalho corporal, em uma sequência de atividades individuais e coletivas, procurando instituir, dessa forma, uma prática específica do fazer teatral: o aquecimento que antecede as propostas de expressão e de criação cênica e que, na maioria das vezes, envolve o corpo inteiro, ou melhor, envolve-nos de corpo inteiro.

As "histórias de corpo inteiro" que narramos aqui foram iniciadas por uma atividade individual, na qual as estudantes se espreguiçavam, ativando e, também, relaxando cada parte do corpo, pois, "ao espreguiçar, liberamos espaço em nossas articulações e equilibramos o tônus muscular no corpo, ou seja, ao espreguiçar, relaxamos regiões tensas do corpo e tonificamos regiões muito relaxadas" (VIANA; STRAZZACAPPA, 2001, p.135). Depois, passamos para a atividade de alongamento, realizando movimentos lentos e precisos, com cada parte do corpo. Todos os movimentos foram demonstrados fisicamente, junto a frases que procuravam estimular as estudantes a deixarem-se surpreender com os próprios movimentos, permitindo que o corpo conduzisse o espreguiçar e o alongar e, também, que bocejos viessem à tona, na intenção de relaxar a musculatura facial e as cordas vocais. A última parte do alongamento foi realizada em duplas, com o intuito de facilitar os movimentos musculares e, também, de impulsionar o contato corporal entre as estudantes. Esse contato continuou a ser estimulado por meio da atividade seguinte, a massagem nos pés, que suscitou sensações, sentimentos, reflexões e questionamentos diferenciados.

Sentadas em roda, cada estudante massageava o pé da colega ao seu lado, ao mesmo tempo em que recebia, de outra colega, a mesma massagem em seu pé. 


\section{Imagem 1: Histórias de Corpo Inteiro}

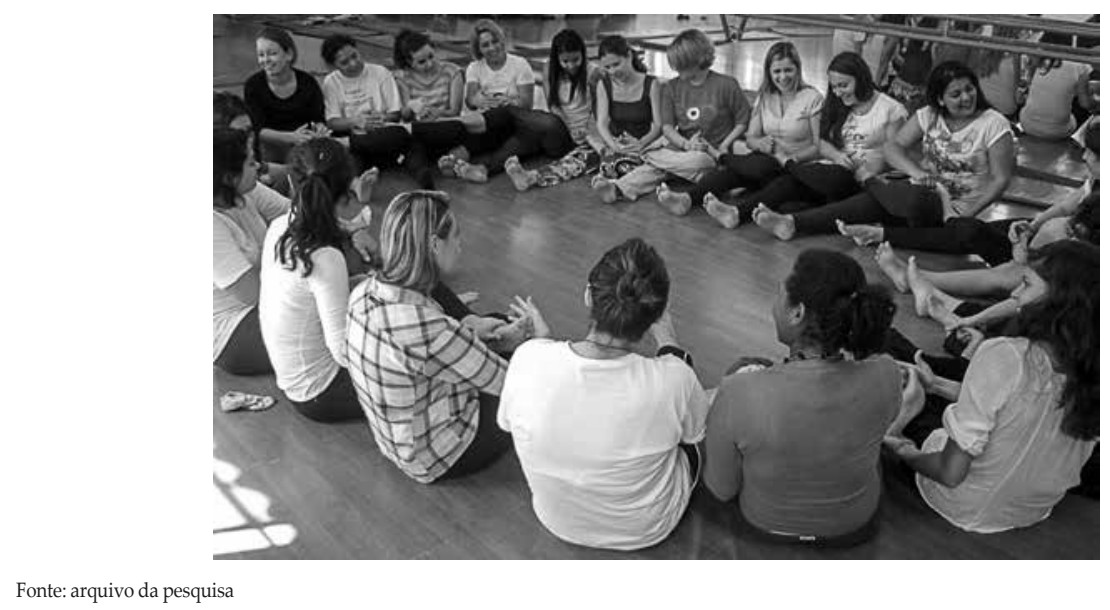

Essa foi uma atividade apreciada por algumas estudantes, mas que não teve a adesão ou a aprovação de todas. Algumas optaram em observar a massagem ou em massagear os próprios pés. Outras, mesmo tendo realizado a atividade, mostraram-se inquietas e apreensivas.

Após a sua realização, conversamos sobre o objetivo daquela massagem, que consiste na vivência de nossas (im)possibilidades de tocar, de se deixar tocar, de estar à vontade com o nosso corpo e com o corpo do outro, uma vez que "a realização do trabalho teatral se dá fundamentalmente com o corpo" (FARIA, 2011, p.127), permitindo o "conhecimento do próprio corpo e uma ampliação das possibilidades de vivência dele e com ele" (FARIA, 2011, p.127). A conversa, porém, não foi suficiente, e nem era essa a sua finalidade, para aplacar a polêmica em torno da massagem nos pés. Em vários outros momentos do curso a atividade foi mencionada em caráter de adesão ou de descontentamento, tanto oralmente como por meio dos registros reflexivos realizados pelas estudantes.

Esses registros, que muito nos auxiliaram a refletir sobre a experiência vivida e aos quais iremos nos reportar ao longo do nosso texto, foram produzidos de duas maneiras: ao final de cada aula - de forma mais aligeirada e pontuando as experiências do dia - e em casa - buscando abarcar a experiência do curso como um todo, realizado em forma de diário e com a utilização de imagens, poemas, formas e materiais variados.

Tanto nos registros realizados ao final da aula em que a massagem foi realizada, como nos diários entregues e socializados ao término do curso, encontramos sensações e sentimentos bastante distintos sobre a experiência de tocar e sentir o toque nos pés. Uma estudante foi categórica: "Eu só não gostei de mexer nos pés dos outros". Outra manifestou seu desconforto, apesar de não ter se recusado a viver a experiência: "Quando tivemos que pegar uma no pé da outra eu não gostei muito não, preferia eu mesma ter tocado nos meus pés". Uma terceira expressou seu estranhamento com certo humor: 
“Fizemos um aquecimento um pouco estranho, pois tínhamos que fazer uma massagem no pé da colega do lado (detalhe: sem meia)!!!”. Houve, também, quem aprovasse sem reservas, como podemos observar em dois trechos que foram retirados de diferentes registros: "Teatro é o corpo a corpo, incluindo pegar no pé uns dos outros. Tem que ser corajoso"; "Ah! Fazer massagem foi muito bom! Receber massagem também é muito bom, a troca de energia, de toque. Ah! Sensibilidade da cabeça aos pés!".

A forma plural como as estudantes se posicionaram sobre a ação, talvez inusitada para algumas, de tocar em pés sem meias e deixar que os próprios pés desnudos fossem tocados, traz indícios da vivência de rupturas com o pré-estabelecido, com as tão conhecidas dicotomias entre certo ou errado, bom ou ruim, permitido ou negado... Quiçá, pequenos passos por entre os caminhos da "jornada de expansão do 'ser professor"' (OSTETTO, 2008, p.127), pressupostos, por esta autora, como "caminhos na direção da integração de polos que, culturalmente, se desconectaram: cognição e afeto, razão e emoção, pensamento e intuição" (idem).

Destacamos, ainda, a potência dessa atividade em instaurar o estranhamento, tão bem captado por uma das estudantes que em sua reflexão final, sobre o curso como um todo, uniu o momento da massagem (utilizando-se de registro fotográfico da atividade) à frase de Bertolt Brecht: "Estranhem o que não for estranho. Tomem por inexplicável o habitual. Sintam-se perplexos ante o cotidiano"(1990, p. 160). Esta frase, retomada pela estudante em seu diário reflexivo, compõe as epígrafes do texto, "Educação Estética e Infância”, de Maria Isabel Leite (2005), por nós discutido na penúltima aula do curso.

\section{Imagem 2: Diário feito com Tecido}

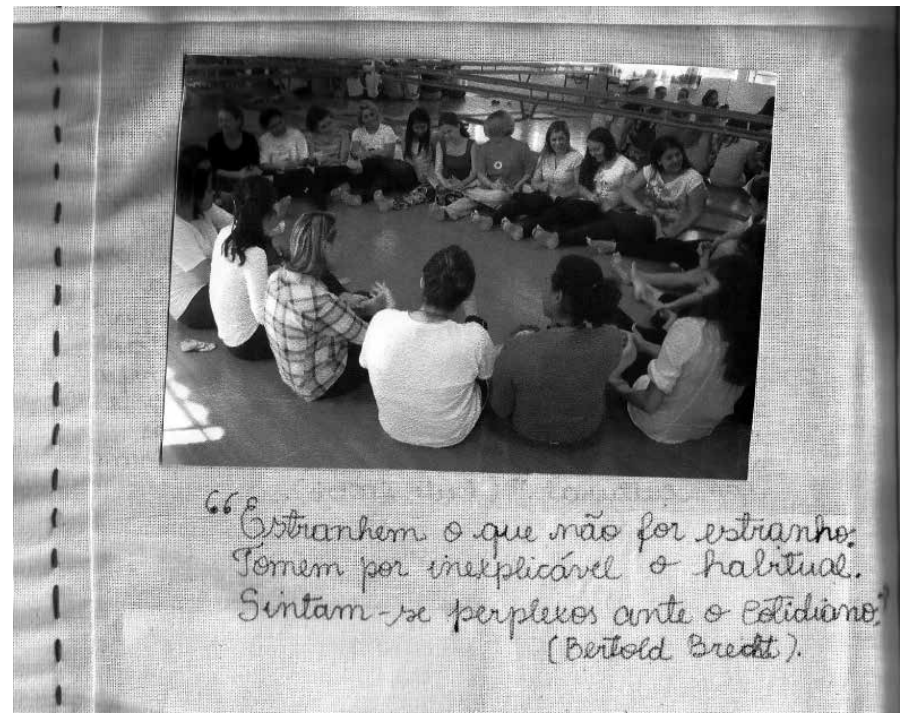

Fonte: arquivo da pesquisa 
Bertolt Brecht viveu na Alemanha, no início do século XX, e suas palavras não podem ser dissociadas do contexto histórico, político e social em que foram escritas. Entretanto, esse contexto, embora distante do nosso em significativos aspectos, é, também, muito próximo no que se refere à necessidade de estarmos atentos e vigilantes quanto ao que se cristaliza em nosso cotidiano, a tudo que se torna habitual, naturalizado e, portanto, sem possibilidade de transformação. A tudo que nos afasta da capacidade "que distingue a espécie humana das outras espécies animais" e que "não nos concilia com um cotidiano em que repetimos, incessantemente, as mesmas práticas pedagógicas esquecidos da emoção de produzir um conhecimento novo" (ALBANO, 2004, p.48).

As "histórias de corpo inteiro" vividas pelas estudantes, futuras professoras de crianças pequenas, trazem implicações à sua formação, uma vez que no âmbito da educação e do cuidado das crianças da educação infantil a necessidade de "estranhar o que não for estranho", como alerta Bertolt Brechet, e de não repetir "as mesmas práticas pedagógicas esquecidos da emoção de produzir um conhecimento novo" (idem), ganha proporções ainda maiores. A criança pede pelo novo, institui a novidade em tudo que faz e diz, imagina e propõe múltiplas formas de conhecer a si e ao mundo, mas para ter acolhidas suas formas novidadeiras e imaginativas depende da parceria da(o)s professora(e)s que, por sua vez, dependem de experiências que lhes possibilitem (re)encontrar com o estranho, com a novidade, com o desejo de desnaturalizar rotinas e procedimentos, cotidianamente.

Passemos, agora, a outras histórias do vivido que aqui narramos e buscamos entrelaçar à discussão sobre a formação e a prática docente de professora(e)s de educação infantil.

\section{Histórias com palavras, sons e movimentos}

Essas histórias aconteceram junto ao encontro com poema Rio na Sombra que faz parte do livro Ou isto ou aquilo, de Cecília Meireles (2002):

Som

frio.

Rio

sombrio.

O longo som

do rio

frio.

O frio 
bom,

do longo rio.

Tão longe,

tão bom,

o claro som

do rio

sombrio!

O livro foi mostrado às estudantes e o poema foi lido em voz alta. Depois, expusemos o chão para que todas pudessem visualizá-lo ao mesmo tempo. Essa exposição foi feita em folhas de papel sulfite, no tamanho A4, com as estrofes do poema escritas com letras grandes.

A segunda leitura foi realizada por todo o grupo, bem devagar, saboreando sua sonoridade. As duas primeiras estrofes foram, então, tomadas como material para a criação de sons e movimentos, realizada por dois grupos.

O grupo A criou e apresentou uma sequência de cinco sons a partir da primeira estrofe do poema:

Som

frio.

Para o grupo $B$ foi proposta a recriação dos cinco sons criada pelo grupo $A$, tornando-os "frios", a partir da maneira de emitir os sons, sem usar movimentos, mudando apenas a forma de produzir os sons vocalmente.

Depois da apresentação dessa recriação, realizada pelas estudantes com muita determinação e animação, o grupo B criou uma sequência de movimentos corporais para a segunda estrofe do poema:

Rio

sombrio.

A sequência foi apresentada e, a partir dela, o grupo A escolheu um som para cada movimento. Feita a escolha, as equipes uniram-se e apresentaram uma obra conjunta: movimentos e sons inspirados nas e pelas palavras "Rio sombrio".

Após essa série de explorações e experimentações vocais e corporais, como última atividade com o poema Rio na Sombra, as estudantes, dividas em cinco grupos, criaram pequenas cenas inspiradas no poema completo. 
Imagem 3: Histórias com Palavras, Sons e Movimentos - Cena 1

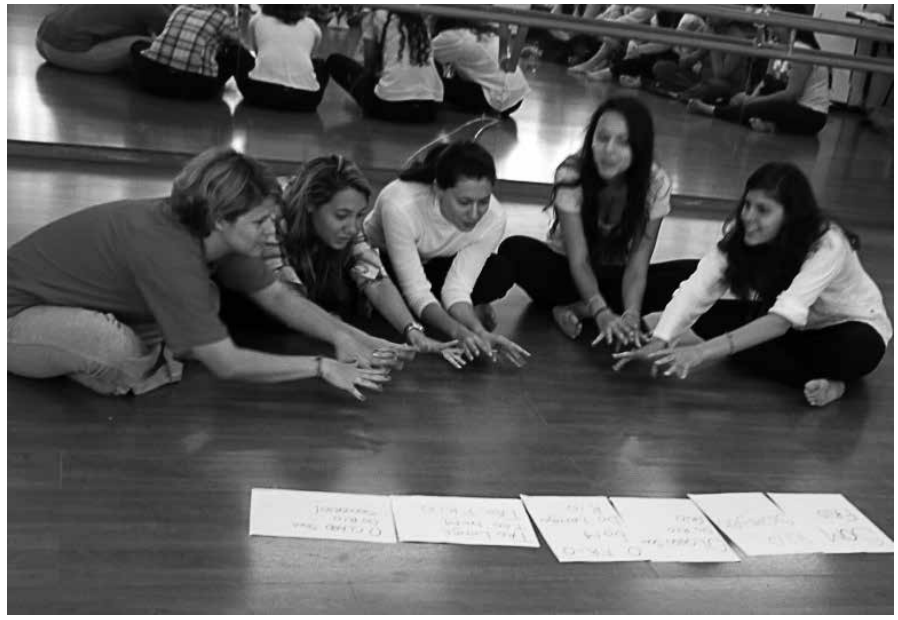

Fonte: arquivo da pesquisa

Imagem 4: Histórias com Palavras, Sons e Movimentos - Cena 2

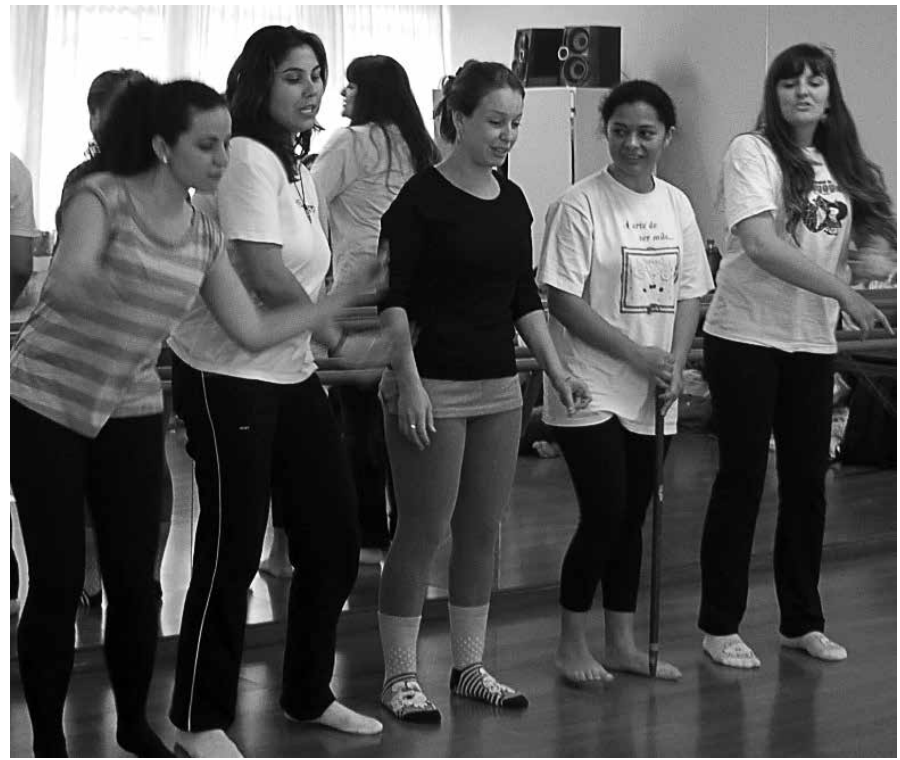


Imagem 5: Histórias com Palavras, Sons e Movimentos - Cena 3

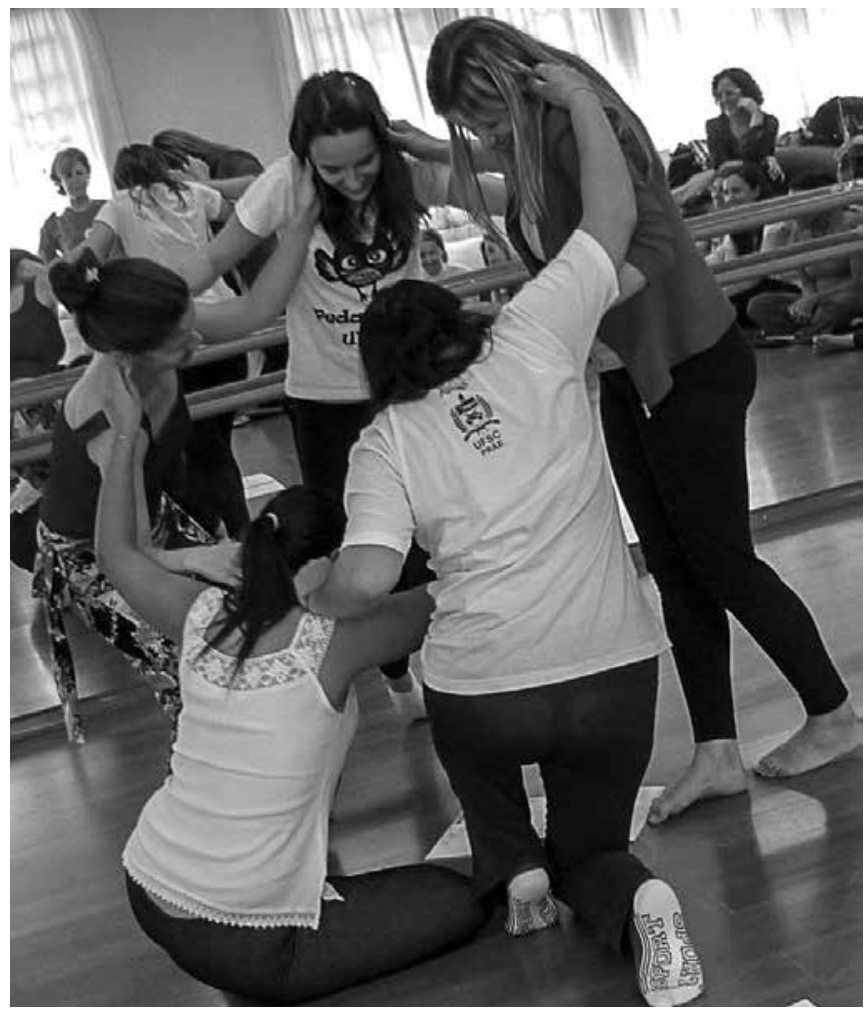

Fonte: arquivo da pesquisa

Imagem 6: Histórias com Palavras, Sons e Movimentos - Cena 4

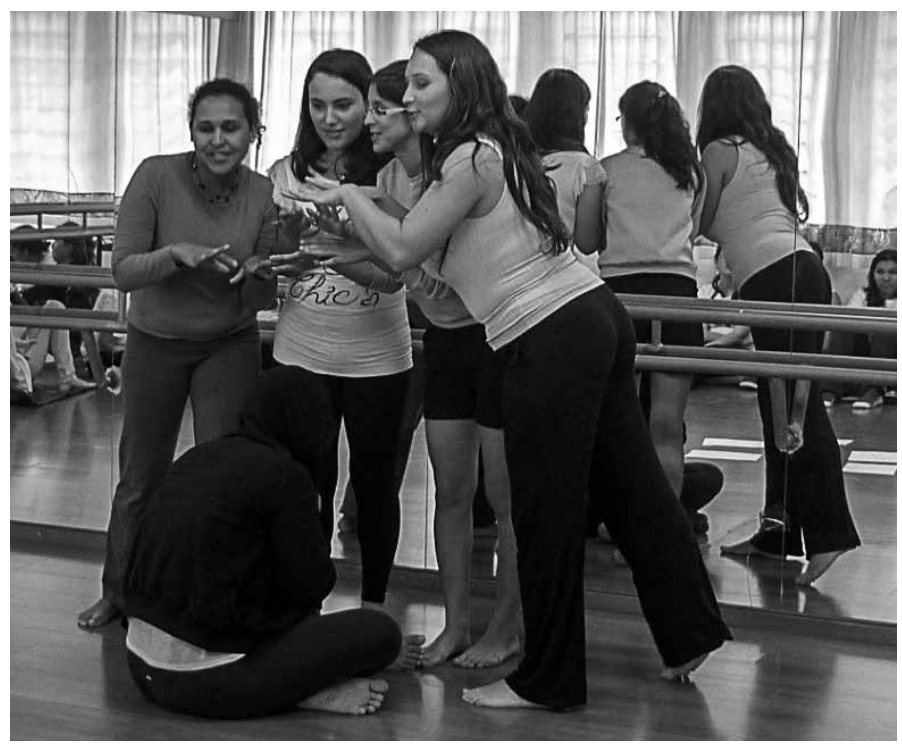

Fonte: arquivo da pesquisa 


\section{Imagem 7: Histórias com Palavras, Sons e Movimentos - Cena 5}

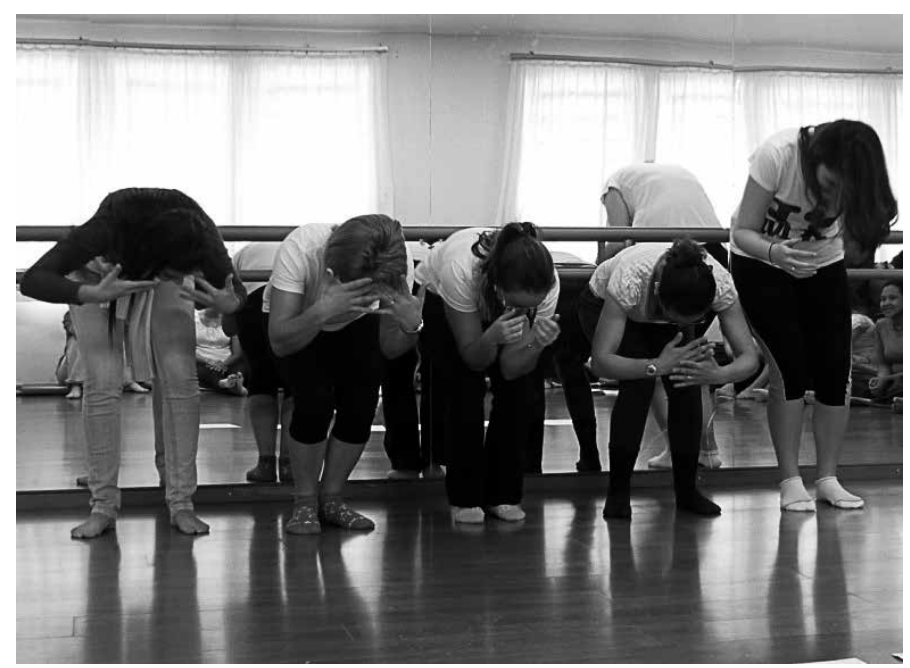

Fonte: arquivo da pesquisa

Essas cenas marcaram a estreia das estudantes na criação cênica em diálogo com obras da literatura para a infância, pois aconteceram no segundo dia do curso. Uma brilhante estreia: alegre, concentrada, interativa, difícil e favorecedora de percepções e aprendizados significativos sobre o encontro com a arte e, também, sobre o que esse encontro pode suscitar, potencializar e solicitar.

Vejamos como essa gama de sentimentos, sensações e (auto)conhecimentos foi tangenciada por algumas das estudantes em suas reflexões produzidas ao final do encontro no qual experienciaram a fruição e a criação cênica a partir do poema de Cecília Meireles.

Nos dois trechos que se seguem, duas das estudantes do grupo ressaltaram a ludicidade e a exploração corporal e sonora da experiência vivida: "Gostei da brincadeira com o poema, nela pudemos usar os movimentos do nosso corpo para expressar sons, isso é muito bom!"; "Os poemas, além de serem interpretados com a voz, também, podem ser interpretados com o corpo e o coração". Estes trechos trazem indícios do modo como suas autoras vivenciaram a brincadeira com o corpo e com a linguagem poética, descobrindo que os poemas, de forma especial os poemas para a infância produzidos no Brasil a partir da segunda metade do século XX, em particular os de Cecília Meireles, têm movimento e este não se concretiza somente nas páginas do livro, mas se estende pelo corpo, ultrapassa a voz e se ramifica na atitude corporal.

Um terceiro trecho, retirado da reflexão de outra estudante, dá continuidade ao mote de descoberta das possibilidades advindas da criação cênica em diálogo com o poema Rio Sombrio:

Gostei de ter feito esta atividade em grupo, porque dá a possibilidade de criar, improvisar, utilizando recursos como música, sons, gestos. É um exercício que exige se soltar e se mostrar para o outro, tentando perder a vergonha e desfrutando do momento da apresentação. Senti um pouco de vergonha, mas foi bom! 
No dizer da estudante percebemos, de forma mais pontual, que no desavergonhamento provocado pelo experienciar da palavra poética em diálogo e parceria com a criação teatral - um estar em lugar até então desconhecido ou muito pouco frequentado em sua adultez alargou-se os passos para outro itinerário, potencializando o seu reencontro com a criação, imaginação, improvisação sonora, musical e gestual, entre outras possibilidades e dimensões que vivenciava quando criança, mas que, muito provavelmente, já havia esquecido. Talvez, por isso, a vergonha de "se soltar e se mostrar ao outro", a vergonha de brincar em grupo.

Asdificuldadescoma criaçãonãoforam poucase duranteocurso, principalmenteemnossas rodas finais, debatemos sobre elas, na intenção de legitimá-las, e aprendermos com sua existência e resistência. No registro que se segue, essas dificuldades se mostram de forma contundente:

Expressar o poema de Cecília Meireles, "Rio na Sombra", foi uma dificuldade terrível. A escuridão não permite enxergar a criatividade, foi necessário sair da caverna em direção à luz! Senti-me amarrada pela falta de criatividade, vergonha e medo de não saber como meu corpo poderia expressar o significado das palavras. Nunca imaginei que um poema poderia transmitir tantas emoções e sensações.

Esse trecho traz a metáfora da caverna para um encontro de luz, e por que não dizer, de liberdade ao descobrir em si outro potencial que não aquele já visível. No (in)visível, vislumbramos o encontro dessa estudante com a emoção e com sensações desconhecidas. Na vivência com o desconhecido a possibilidade de reconstruir-se, ver-se outra. Uma possibilidade que foi se adensando no decorrer do curso, como ela mesma pôde descobrir e nos contar por meio do seu diário reflexivo: criado por objetos que diziam da sua experiência com as linguagens da arte vivida em nossa companhia.

\section{Imagem 8: Diário feito com Objetos}

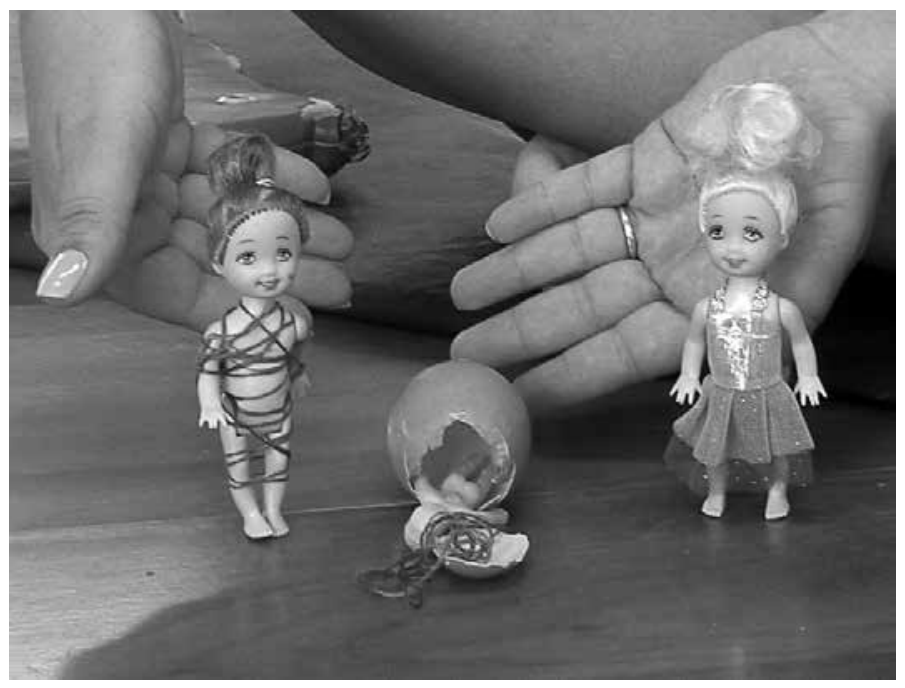

Fonte: arquivo da pesquisa 
[...] quando começou esse curso eu me sentia muito amarrada, sem conseguir me expressar com o meu corpo e era uma sensação muito ruim. Então, trouxe essa bonequinha para demonstrar que eu me sentia muito amarrada e com o decorrer do curso eu fui conseguindo me expressar melhor e sair desse ovo que eram as amarras, que era a vergonha, a falta de criatividade. Fui saindo e, no final do curso, eu fiquei livre (trecho da socialização do diário, gravada em vídeo).

\section{Os últimos fios da tessitura pretendida}

Reflexões sobre uma vida adulta distante do brincar, da criação, de vivências imaginativas e poéticas e as implicações dessa distância à formação e à prática pedagógica de professora(e)s de crianças têm sido realizadas por diferentes autores ${ }^{2}$. No livro O espaço do desenho: a educação do educador, Ana Angélica Albano (2012) reflete e nos convida a refletir sobre a recuperação do ser poético da criança - muitas vezes já perdido ou tão pouco valorizado - e do professor. Diz a autora que o "importante é que cada um possa reencontrar o seu próprio canal expressivo: desenhar com palavras, com a música, com as cores, com o gesto. E também se aventurar em outras linguagens, recriando seu espaço lúdico, afirmando-se como ser humano" (p. 80). E, mais adiante, reafirma a relação entre o professor que reencontra com a criação artística e os caminhos oferecidos por ele à expressão e à criação poética da criança: "recuperar o ser poético que é a criança só é possível quando os professores se percebem como pessoas ainda capazes de viver o estranhamento, que é o ser da poesia, quando o professor descobre nele mesmo o prazer da criação" (p.107).

Em nossa experiência, a recuperação do ser poético das futuras professoras de crianças foi potencializada por meio do encontro entre a linguagem teatral e a literatura produzida para a infância. Por meio de um processo, embora curto, contínuo e focado exclusivamente na experimentação de linguagens artísticas e no qual significação e expressão de ideias, sentimentos e conhecimentos não ocorreram somente pelas formas linguísticas que informam, mas, também, por aquelas que potencializam a imaginação, concretizam-se por meio dos movimentos do corpo, dos sons, das cores, dos ritmos, das brincadeiras... Formas linguísticas que constituem os modos de "expressão e manifestação infantis e, ao mesmo tempo, são as bases fundadoras da constituição do conhecimento pela criança" (ROCHA e OSTETTO, 2008, p.112), mas que, nem sempre, são experienciadas e exploradas por professora(e) s ou futura(o)s professora(e)s de educação infantil em processos de formação docente.

Descobrir (-se), conhecer (-se) e dizer de si e do mundo, fruindo e utilizando, além das palavras que informam, palavras poéticas, sons, movimentos, diferentes ritmos, metáforas, brincadeiras... foram ações vivenciadas pelas estudantes que, como pudemos observar em suas reflexões, também valorizaram essas possibilidades advindas da experiência de fruição e de criação artística. Suas palavras evidenciam o processo de estranhamento, descoberta, desacomodação, aprendizado e também a valorização desse processo. 
Se professora(e)s e futura(os) professora(e)s, em sua maioria, são adultos já desacostumada(o)s com um mundo (di)verso e pleno de inventividade, necessitam, também, de tempos e espaços para reencontrar e desenvolver suas muitas/múltiplas/ diferentes linguagens, na perspectiva de terem ampliadas suas possibilidades de expressão e formas de conhecer, assim como, de acolher, valorizar e potencializar essas mesmas possibilidade juntos às crianças pequenas.

A forma de ser e estar no mundo das crianças possui especificidades que muitas vezes não são acessadas pelos adultos. Alguns costumam dizer que "as crianças vivem no mundo da lua" para se referirem a sua inconstância ou falta de conformidade a muitas regras ou condutas, mas não se atentam que o mundo em que vive a criança é feito de desajustamento e transformação, como o retrataram Souza e Pereira (1998):

A criança contém em germe a experiência - essencial ao homem - do seu desa-
justamento em relação ao mundo, enfim, a experiência de sua não soberania. A
incapacidade infantil de não entender certas palavras e manusear os objetos dando-
-lhes usos e significações ainda não fixados pela cultura nos faz lembrar que tanto
os objetos como as palavras estão no mundo para serem permanentemente resigni-
ficados através das nossas ações. [...] O mundo em que a criança vive suas relações
com o outro é um claro escuro de verdade e engano. Neste mundo, a verdade não é
dada, não está acabada, impressa de forma imutável na consciência humana; a ver-
dade é algo que se faz constantemente nas relações sociais e por meio delas [...] (s/p).

Um mundo que possui características distintas do mundo em que vive o adulto. A criança, diferentemente do adulto, ainda não vive as certezas e sim as descobertas, principalmente as crianças pequenas, de 0 a 5 anos. Nesse sentido, construir saberes e fazeres acerca da prática pedagógica com crianças da educação infantil é, também, desestabilizar o mundo das certezas adultas. É, sobretudo, aceitar a existência de outras lógicas, o que, em alguma medida, pode potencializar no adulto a compreensão do conceito de culturas da infância como "uma lógica particular acionada pelas crianças a todo o momento para dar sentido às suas experiências, suas formas de pensar e de sentir, específicas na infância, das crianças e seus pares, distintas dos adultos, mas não independentes destas $^{\prime \prime 3}$ (CANAVIEIRA; CALDEIRON, 2011, p. 156). Se quisermos que professora(e)s e futura(o)s professora(e)s qualifiquem a lógica da infância é preciso que possam conviver com lógicas plurais, sendo os processos de fruição e de criação artística um caminho certeiro para tal empreitada, pois ela, a arte, é constituída por lógicas plurais, nela residem tais lógicas e por meio dela acedemos à pluralidade que nos constituem, apesar de já bastante desbotada e amortecida pelo mundo das certezas.

Como disse o escritor uruguaio Eduardo Galeano, em entrevista para o Programa Sangue Latino", "as crianças têm a capacidade de beleza, de formosura, [...] o que acontece é que depois nós, adultos, ocupamo-nos em transformá-las em nós mesmos". Nessa mesma entrevista, Galeano, ainda falando sobre crianças, narra um encontro seu com uma delas: 
Saí a caminhar aqui pelo bairro, era cedo, de manhazinha [...], cruzei com uma menina, muito nova, devia ter uns dois anos, não mais que dois e que vinha brincando na direção oposta [a minha]. Ela vinha cumprimentando a grama, a graminha, as plantinhas: "Bom dia, graminha", ela dizia, "bom dia, graminha!". Ou seja, nessa idade [...] somos todos poetas, depois o mundo se ocupa de apequenar nossa alma e é a isso que chamamos crescimento, desenvolvimento.

Tanto esse, como outros artistas percebem a intimidade da infância com a dimensão poética. O poeta Manoel de Barros, por exemplo, disse ao editor de sua obra autobiográfica, Memórias Inventadas (2006), que não seria capaz de escrever sobre a mocidade e sobre a velhice porque só teve infância, sendo, então, aconselhado por ele a "inventar" as memórias da segunda e da terceira infância (SOTO, 2006). Para nós, e para tantas outras pessoas que estudam e vivem a interface da arte com a infância, é urgente que essa intimidade entre infância e dimensão poética invada, encharque, inunde a formação e as práticas pedagógicas de professora(e)s e de futura(os) professora(e)s de creches e pré-escolas.

Recebido em: 02/07/2018 e aprovado em: 17/08/208

\section{Notas}

1 Sobre esse sistema ver (SPOLIN, 2008; 2001; 1999; 1987), (KOUDELA, 1990), (JAPIASSU, 2007; 2001), (FARIA, 2011), entre outros.

2 Sobre essa questão ver, Albano (2012), Cintra e Albano (2010), Cintra e Debus (2012), Dias (2007), Leite e Ostetto (2004), Ostetto (2006), entre outros.

3 As autoras ao definirem culturas da infância baseiam-se em SARMENTO (2005).

4 Gravado em 2009, produzido e exibido pelo Canal Brasil. Direção de Felipe Nepumuceno. Disponível em http://www.youtube.com/watch?v=w8rOUoc_xKc. Acesso em: 23/03/2012.

\section{Referências}

ALBANO, Ana Angélica. O espaço do desenho: a educação do educador. 15ª ed. São Paulo: Loyola, 2012.

ALBANO, Ana Angélica. A arte como base epistemológica para uma pedagogia da infância. In: Caderno Temático de formação II: SÃO PAULO. Educação Infantil construindo a Pedagogia da Infância no município de São Paulo. São Paulo: Prefeitura Municipal de São Paulo Secretaria Municipal de Educação, 2004.

BARROS, Manoel de. Memórias Inventadas: a segunda infância. Iluminuras de Marta Barros. São Paulo: Planeta do Brasil, 2006. 
BRECHT, Bertolt. Teatro Completo, em 12 volumes. Rio de Janeiro: Paz e Terra, 1990.

BOCHECO, Eloí. Rua âmbar. Il. Márcia Cardeal. São Paulo: Formato, 2013.

CANAVIEIRA, Fabiana O.; CALDEIRON, Ana Cláudia. Relações entre as crianças pequenas e a produção das culturas infantis: vistas, ouvidas e citadas. In: GEPEDISC. Culturas Infantis em creches e pré-escolas: estágio e pesquisa. Campinas: Autores Associados, 2011. p. 154-171.

CINTRA, Simone C. S.; DEBUS, Eliane D. S. Formação estética de educadores: diálogos entre os fazeres da arte e da educação para a infância. Revista Contrapontos, Itajaí, Univali, v. 12, n. 3, p. 290-298, set./ dez. 2012.

FARIA, Alessandra Ancona de. Contar histórias com o jogo teatral. São Paulo: Perspectiva, 2011.

JAPIASSU, Ricardo. A linguagem do teatro na escola: pesquisa, docência e prática pedagógica. Campinas: Papirus, 2007.

JAPIASSU, Ricardo. Metodologia do ensino de teatro. Campinas: Papirus, 2001.

KOUDELA, I. D. Jogos Teatrais. $2^{2}$ ed. São Paulo: Papirus, 1990.

LEITE, Maria Isabel. Educação Estética e Infância. Cadernos de Pesquisa em Educação, Vitória: UFES, v.11, n. 22, p. 94-105, jul./dez. 2005.

LEITE, Maria Isabel; OSTETTO, Luciana E. Formação de Professores: o convite da arte. In: OSTETTO, Luciana E.; LEITE, Maria Isabel (Org.). Arte, Infância e formação de professores: autoria e transgressão. Campinas: Papirus, 2004, p.11-24.

MEIRELES, Cecília. Rio na Sombra. In: MEIRELES, Cecília. Ou isto ou aquilo. Il: Thais Linhares. $6^{a}$ ed. Rio de Janeiro: Nova Fronteira, 2002.

OSTETTO, Luciana E. Educadores na roda da dança: formação - transformação. Campinas, 2006. 250f. Tese (Doutorado em Educação) - Universidade Estadual de Campinas, Campinas, 2006.

OSTETTO, Luciana E. O estágio curricular no processo de tornar-se professor. In: (Org.).

Educação Infantil: saberes e fazeres da formação de professores. Campinas: Papirus, 2008. p.127-138.

PRADO, Guilherme do Val Toledo; SOLIGO Rosaura. Memorial de Formação: quando as memórias narram a história de formação. In: PRADO, Guilherme do Val Toledo; SOLIGO Rosaura (Orgs.). Porque escrever é fazer história. Campinas: Graf. FE, 2005, p. 47-62.

ROCHA, Eloísa A. C; OSTETTO, Luciana Esmeralda. O estágio na formação universitária de professores de Educação Infantil. In: SEARA, Izabel Christine et al. (Orgs.). Práticas pedagógicas e estágios: diálogos com a cultura escolar. Florianópolis: Letras Contemporâneas, 2008, p. 103-116.

SARMENTO, Jacinto Manuel. Gerações e alteridade: interrogação a partir da sociologia da infância. Educação \& Sociedade: Revista de Ciências da Educação, Campinas: CEDES, v. 26, n. 91, p.361-378, mai./ago. 2005.

SOTO, Pascoal. Orelha. In: BARROS, Manoel de. Memórias Inventadas: a segunda infância. Iluminuras de Marta Barros. São Paulo: Planeta do Brasil, 2006.

SOUZA, Solange Jobim; PEREIRA, Rita Marisa Ribes. Infância, conhecimento e contemporaneidade. 21ª Reunião anual da Anped. GT7 - Educação Infantil. Caxambu. 1998. Disponível em: http://www. ced.ufsc.br/ nee0a6/anped.html. Acesso em: 23/03/2012.

SPOLIN, Viola. Jogos teatrais na sala de aula: um manual para o professor. São Paulo: Perspectiva, 2008. 
SPOLIN, Viola. Jogos teatrais: o fichário de Viola Spolin. São Paulo: Perspectiva, 2001.

SPOLIN, Viola. O jogo teatral no livro do diretor. São Paulo: Perspectiva, 1999.

SPOLIN, Viola. Improvisação para o teatro. São Paulo: Perspectiva, 1987.

VIANA, Tiche; STRAZZACAPPA, Márcia. Teatro na Educação: Reinventando Mundos. In: FERREIRA, Sueli (Org.). $O$ ensino das Artes: construindo caminhos. Campinas: Papirus, 2001, p.115-138. 